\title{
Inputs from Philosophy to Cognitive Science: the Example of L-concepts and the Suppression Task
}

\author{
Miguel López-Astorga \\ Institute of Humanistic Studies "Juan Ignacio Molina", University of Talca, Chile \\ Email address: milopez@utalca.cl
}

\begin{abstract}
Although it is many times said that progress can be observed in none of the different subfields that are part of philosophy, this paper is intended to show otherwise by means of an example. That example is based upon the L-concepts that are introduced by Carnap in his method of extension and intension, and it refers to the idea that the underlying machinery of this last method is able to solve problems such as those that reasoning exercises such as the suppression task raise in the cognitive science field nowadays. As it is accounted for, the key is to assume that the human mind is somehow linked to state-descriptions akin to those proposed by Carnap.
\end{abstract}

Keywords: Carnap; method of extension and intension; semantics; state-descriptions; suppression task

\section{Introduction}

People often think that there is no progress in philosophy, philosophy has nothing to do with science, and, therefore, the former cannot deliver anything to the development of knowledge. However, this paper tries to show that this view is not absolutely correct, at least, as far as cognitive science is concerned.

Indeed, it is clearly possible to find in the philosophical tradition approaches with the conceptual elements enough to solve certain cognitive problems. That can be, for instance, the case of Chrysippus of Soli and his criterion to decide when a conditional is sound, which, as explained in López-Astorga (2017), seems to be able to solve even difficulties such as those presented by the four cards selection task proposed by Wason $(1966,1968)$.

Thus, another example of how another problem of current cognitive science can be overcome by virtue of essentially philosophical tools will be provided here. The philosophical framework will be much more contemporary than that of Chrysippus, as it will be the one of Carnap's (1947) method of extension and intension. On the other hand, the cognitive problem will be that of the suppression task (e.g., Byrne, 1989), a very simple reasoning exercise that, nevertheless, is controversial between the cognitive scientists because of the debates it causes regarding the possible solutions for its difficulties.

In this way, following what has been said, the structure of the paper is obvious. Firstly, what the suppression task is exactly will be commented on. Secondly, the elements of the method of extension and intension by Carnap (1947) that are necessary to address the difficulties of the aforementioned task will be described (as it will be shown, to deal with such difficulties it is not needed to assume all of the Carnap's ideas; not even all of the theses and assumptions involved in his method of extension and intension must be considered to do that). Finally, it will be explained

(C) AesthetixMS 2020. This Open Access article is published under a Creative Commons Attribution Non-Commercial 4.0 International License (http://creativecommons.org/licenses/by-nc/4.0/), which permits non-commercial re-use, distribution, and reproduction in any medium, provided the original work is properly cited. For citation use the DOI. For commercial re-use, please contact editor@rupkatha.com. 
how, certainly, from those elements it is possible to give an answer to the problems that are related to the suppression task.

\section{The suppression task}

Actually, there are different versions of the suppression task. It was already used in works such as that of Byrne (1989), but since then many different researches of very different kinds have resorted to it too, including studies aimed to analyze the cognitive abilities of people with autism (e.g., Pijnacker, Geurts, Van Lambalgen, Kan, Buitelaar, \& Hagoort, 2009). Nonetheless, it can be stated that a more or less standard version can be as follows:

[I]

"a. If Mary has an exam, she will study in the library

b. If the library is open, Mary will study in the library

c. Mary has an exam

d. Will Mary study in the library?" (Pijnacker et al., 2009, p. 645).

As pointed out, many more versions with certain variations are to be found in the specialized literature. However, [I] is illustrative enough to understand the problems of this task. Its answer is absolutely clear from the logical point of view, as, if [I.a] and [I.c] are taken into account and Modus Ponendo Ponens is applied to them, the conclusion is that, indeed, Mary will study in the library. Nevertheless, most participants in tasks such as [I] often respond something similar to that it is not possible to know for sure whether Mary will study in the library.

One might think that this difficulty is really easy to eliminate: it is enough to assume the idea that the human mind does not work by considering logic. Nonetheless, the truth is that the difficulty does not disappear so simply. There are theories such as that of the mental logic theory (e.g., Braine \& O'Brien, 1998a) that propose that, while people reason in accordance with a logic, that logic is not the classical one. These theories are often based upon empirical evidence and only accept as true mental rules the schemata that, according to experimental results, are really used by individuals. But empirical evidence shows, precisely, that Modus Ponendo Ponens is a rule that people almost always use, and hence this type of theories usually admits this last rule as an essential human reasoning rule (see, e.g., Braine \& O’Brien, 1998b).

On the other hand, there are also theories that claim that there is no logic of any kind in the human mind, and that the mental mechanisms why people make inferences have nothing to do with logic. This is the case of, for example, the mental models theory (e.g., Bucciarelli \& JohnsonLaird, 2019; Khemlani, Byrne, \& Johnson-Laird, 2018; Khemlani, Hinterecker, \& Johnson-Laird, 2017; Quelhas \& Johnson-Laird, 2017; Quelhas, Rasga, \& Johnson-Laird, 2017). However, the problem for theories such as this last one keeps being the same: if, beyond logic, people generally make inferences with premises with a grammatical structure akin to 'if $A$, then B' and ' $A$ ', which, beyond Modus Ponendo Ponens, is the grammatical structure corresponding to [I.a] and [I.c], and come to conclusions similar to ' $\mathrm{B}$ ', it continues to be necessary to explain the reason why the suppression task is not often responded with a positive response.

Nonetheless, as mentioned, the method of extension and intension offered by Carnap (1947) can help solve these difficulties. It is only necessary to pay attention to some of its basic elements. 


\section{Some important elements of the method of extension and intension}

As also mentioned, to understand the problem of the suppression task it is not needed to accept all of the elements of Carnap's (1947) method. Only some of them are necessary. One of them is the concept of 'state-description'. According to Carnap (1947), a state description is exactly what Leibniz considers to be a 'possible world', or what Wittgenstein considers to be a 'possible state of affairs'. So, the links to modal logic are clear.

However, what is truly interesting about state-descriptions is that they allow defining other important elements, for example, L-concepts, that is, the concepts that refer to the truth or falsehood of formulae by considering exclusively the language that is being used. In this way, a formula is L-true if and only if it is so exclusively by virtue of the language. Thus, it can be said that the sentences that are L-true are, as Carnap explicitly acknowledges, analytic in the Kantian sense of this last word. But, if a formula, or a sentence, is L-true, or analytic, it is evident that it is also true in all of the possible worlds one can suppose, that is, in all state-descriptions.

And, from this general framework, Carnap (1947) derives other relevant definitions. For example, given the definition of L-truth, the one of L-falsehood is obvious: a formula, or sentence, is Lfalse, or analytically false (i.e., a contradictory formula or sentence), if and only if it is false in all state-descriptions. Likewise, he explicitly provides links to modal logic as well. A formula, or sentence, will be necessary if and only if it is L-true. In the same way, a formula, or sentence, will be impossible if and only if it is L-false. Thus, clearly, a formula, or sentence, will be possible if and only if it is true, at a minimum, in one state-description. And this last concept also leads to concepts such as that of F-truth, which refers to the situation in which a formula, or sentence, is true not by virtue of the language, but by virtue of facts. Accordingly, that a formula, or sentence, is F-true means, as Carnap also explicitly indicates, that it is synthetic in the Kantian sense of the word, and that it should be true, at a minimum, in one state-description, and it should be false, at a minimum, in another state-description.

But maybe the most important definition for the goals of this paper is the one of L-implication. Given a formula such as the following:

[II] $\quad \mathrm{p} \rightarrow \mathrm{q}$

(Where ' $\rightarrow$ ' provides conditional relationship)

L-implication happens when [II] is L-true, or, if preferred, analytic, or, if preferred, necessary.

Of course, Carnap's (1947) method of extension and intension is much more complex than what has been commented on in this section. Nevertheless, the definitions and concepts indicated suffice to explain the problem of the suppression task (in fact, there are already works that take only some aspects of Carnap's method to account for logical and philosophical problems; see, e.g., López-Astorga, 2018a). The next section is devoted to that explanation.

\section{The suppression task and state-descriptions}

In principle, one might think that Modus Ponendo Ponens has to be absolutely correct under Carnap's (1947) method. If a sentence with the form of [II] and a sentence being just the antecedent of [II] are assumed as premises, the conclusion should be the consequent of [II], no matter whether the premises are true only in one state-description, in some of them, or in all of 
them. Thus, the only requirement seems to be that the two premises hold, at least, in the statedescription to which the inference refers.

Certainly, it can be claimed that this is exactly what occurs many times, since, as said, people often apply Modus Ponendo Ponens, the suppression task being clearly an exception. This can be checked, for instance, in the cases in which the version of the suppression task only includes two premises, and, keeping taking the sentences indicated in [I] into account, the task that is really proposed to participants consists of, for example, just [I.a], [I.c], and [I.d]. In cases such as this one, individuals almost always give the correct response and state that Mary will study in the library (see, e.g., Pijnacker et al., 2009).

Why is the situation different when the premises are three? As also pointed out, that is not difficult to explain if the elements of Carnap's (1947) method of extension and intension described in the previous section are assumed. It is obvious that in [I] the first premise, that is, [I.a], is neither L-true nor necessary, and that, therefore, the fact that Mary has an exam does not Limplies that she studies in the library, because the language, in this particular case, English, offers no semantic connection between having an exam and studying in a library. However, as indicated too, this would not be a problem if one could think that [I.a] and [I.c] are true in the same statedescription (as it happens when the task lacks a premise such as [I.b]). The difficulty of [I] is hence that there is something in it that does not enable to think in that way, and that is, evidently, premise [I.b].

Indeed, premise [I.b] reveals that [I.a] and [I.c] may not be true in the same state-description. The semantic information provided by it shows that there is at least one state-description in which Mary has an exam and she does not study in the library. And that state-description is the one in which, in spite of the fact that Mary has an exam, she cannot study in the library because the library is closed.

So, considering that [I.a] has the formal structure indicated in [II], it can also be said that there is at least one state-description in which $\mathrm{p}$ is true and $\mathrm{q}$ is not. This is a problem in no manner, as [I.a.] is, as indicated, F-true. Accordingly, there is nothing unusual about the fact that people do not know for sure which the correct answer for [I] is. In fact, what should be expected is, precisely, that they do not know for sure it. And this is so because the point is that information about in which exact state-description Mary actually has the exam is missing.

\section{Conclusions}

Evidently, explanations similar to the one above can also be offered for versions of the suppression task in which the content is different or the two first premises have a different position in the inference (of course, many versions of the suppression task with characteristics such as those are to be found in the cognitive science literature). Nonetheless, what is truly important is that perhaps, if cognitive science paid more attention to philosophical proposals in the past, it could find interesting resources to solve some of its problems at present. The suppression task and its difficulties is just an example, and it is obvious that many more examples can be considered. One of them is clearly, for instance, as indicated, the one of the four cards selection task raised by Wason $(1966,1968)$, whose problems, according to López-Astorga (2017), can be addressed from the view of the conditional provided by Chrysippus of Soli. 
But, on the other hand, it is also evident that the concept of L-implication can be easily related to approaches such as the one of Lewis (1918). Carnap (1947) appears to be absolutely aware of this. However, maybe the point can be that Lewis' proposal has been in turn linked somehow to the one of Chrysippus too (e.g., Gould, 1970), which suggests that it is possible that some of the theoretical tools that can be necessary to understand certain difficulties that cognitive science faces at present can already be found in Ancient Greece. There is no doubt that such tools can be in Greece underdeveloped and, in the way Greek philosophers presented them, need more further elaboration. Nonetheless, what has been stated seems to show that science can still find relevant inputs in the philosophical historical tradition today.

Furthermore, undoubtedly, it is true that a current theory coming from psychology can remove the problems of tasks such as that of suppression. That theory, which is the mental models theory, has a strong empirical support. Nevertheless, this theory is very interested in modality, and, although it explicitly rejects relationships in that way (e.g., Khemlani et al. , 2017), it has been argued that some of its concepts are very similar to those of possible worlds (e.g., López-Astorga, 2018b) and, accordingly, of state-descriptions (for relations between the mental models theory and Carnap's philosophy, see also, e.g., López-Astorga, 2018a). In fact, one might think that perhaps the account that, from the mental models theory, could be given for the difficulties of the suppression task would not be very different, in its essential structure, from the one offered here. However, to develop this point, which would be really interesting, is beyond the aims of this work. Such aims refer to simply show the possibilities of Carnap's (1947) approach to explain the suppression task, and, as stated, it appears that such possibilities cannot be ignored even accepting the mental models theory.

In this way, what is truly important is that, having said all that, strictly speaking, it cannot be claimed that progress cannot be found in philosophy in any sense, that it has nothing to do with science, or that it is never an actual input for knowledge development. At a minimum, it can be said that, if elements such as those coming from the method of extension and intension taken into account here are adopted, the difficulties of a task such as the suppression task can be eliminated. So, it cannot be said that philosophy has no relationship to progress. Likewise, if cognitive studies are deemed as scientific studies (and, probably, there is no reason to think otherwise), for the same reason, it cannot be claimed that philosophy is absolutely different from science. And, if all of this is so, keeping insisting on that philosophy does contribute to scientific knowledge can be even trivial.

\section{Acknowledgments}

This paper is a result of the project CONICYT/FONDECYT/REGULAR/FOLIO № 1180o13, "Recuperación de las formas lógicas de los enunciados a partir de un análisis de las posibilidades semánticas a las que hacen referencia”, supported by the National Fund for Scientific and Technological Development (FONDECYT, following its initials in Spanish), Government of Chile. 


\section{References}

Braine, M. D. S. \& O’Brien, D. P. (Eds.) (1998a). Mental Logic. Mahwah, NJ: Lawrence Erlbaum Associates, Inc., Publishers.

Braine, M. D. S. \& O'Brien, D. P. (1998b). The theory of mental-propositional logic: Description and illustration. In M. D. S. Braine \& D. P. O’Brien (Eds.), Mental Logic (pp. 79-89). Mahwah, NJ: Lawrence Erlbaum Associates, Inc., Publishers.

Bucciarelli, M. \& Johnson-Laird, P. N. (2019). Deontics: Meaning, reasoning, and emotion. Materiali per una Storia della Cultura Guiridica, XLIX(1), 89-112.

Byrne, R. M. J. (1989). Suppressing valid inferences with conditionals. Cognition, 31, 61-83.

Carnap, R. (1947). Meaning and Necessity: A Study in Semantics and Modal Logic. Chicago, IL: The University of Chicago Press.

Gould, J. B. (1970). The Philosophy of Chrysippus. Albany, NY: State University of New York Press.

Khemlani, S., Byrne, R. M. J., \& Johnson-Laird, P. N. (2018). Facts and possibilities: A model-based theory of sentential reasoning. Cognitive Science, $42(6)$, 1887-1924.

Khemlani, S., Hinterecker, T., \& Johnson-Laird, P. N. (2017). The provenance of modal inference. In G. Gunzelmann, A. Howes, T. Tenbrink, \& E. J. Davelaar (Eds.), Proceedings of the $39^{\text {th }}$ Annual Conference of the Cognitive Science Society (pp. 259-264). Austin, TX: Cognitive Science Society.

Lewis, C. I. (1918). A Survey of Symbolic logic. Berkeley, CA: University of California Press.

López-Astorga, M. (2017). Chrysippus' logic and Wason's selection task. In P. Hanna (Ed.), An Anthology of Philosophical Studies. Volume 11 (pp. 47-56). Athens, Greece: Athens Institute for Education and Research (ATINER).

López-Astorga, M. (2018a). An axiom linking necessity and obligation provided by Prior and its analysis under Carnap's method. Logos and Episteme, 9(4), 403-412.

López-Astorga, M. (2018b). Iconic representations, possible worlds, and system K. Analele Universitatii din Craiova, Seria Filosofie, 42(2), 120-136.

Pijnacker, J., Geurts, B., Van Lambalgen, M., Kan, C. C., Buitelaar, J. K., \& Hagoort, P. (2009). Defeasible reasoning in high-functioning adults with autism: Evidence for impaired exception-handling. Neuropsychologia, 47(3), 644-651.

Quelhas, A. C. \& Johnson-Laird, P. N. (2017). The modulation of disjunctive assertions. The Quarterly Journal of Experimental Psychology, 70(4), 703-717.

Quelhas, A. C., Rasga, C., \& Johnson-Laird, P. N. (2017). A priori true and false conditionals. Cognitive Science, 41(55), 1003-1030.

Wason, P. C. (1966). Reasoning. In B. Foss (Comp.), New Horizons in Psychology (pp. 135-151). Harmondsworth (Middlesex), UK: Penguin.

Wason, P. C. (1968). Reasoning about a rule. Quarterly Journal of Experimental Psychology, 20, 273-281. 